\title{
OTAF Score: A Novel Scoring System for Selection of an Ideal Local and Locoregional Flap for Oncoplastic Head and Neck Reconstruction
}

\author{
MOHAMED A. WAHSH, M.D. \\ The Department of General Surgery, Plastic \& Reconstructive Surgery Unit, Faculty of Medicine, Zagazig University
}

\begin{abstract}
Introduction: Modern trends in post malignancy reconstruction target more aesthetic and functional outcome with more patient satisfaction. This study aims to weight the oncological, technical, aesthetic and functional considerations and propose a novel scoring system in selection of an ideal local and locoregional flap for oncoplastic head and neck reconstruction.

Patients and Methods: 52 local and locoregional flaps were created in 52 patients those were squeduled for head and neck tumour resection and defects reconstruction. These cases have been classified into six groups according to the flaps used in reconstruction. Oncological, technical, aesthetic and functional considerations were reviewed in each case. The data were collected as a prospective study throughout a 2-year period.
\end{abstract}

Results: By analysis of the pre-requisites, operative findings and outcomes of reconstructions, multipleparameters; oncological, technical, aesthetic and functional were evaluated. All significant positive considerations were grouped and compared in each flap type. According to the weight of these considerations, a proposal of a scoring system (OTAF score) was formulated.

Conclusion: This study provides a simplified systematic method of flap selection for post malignancy head and neck reconstruction through a scoring system (OTAF score) using oncological, technical, aesthetic and functional considerations. Individualized selection for each case still has its place however further evaluation and modifications of this scoring system is essential to maximize the results of our reconstructive tools.

Key Words: Locoregional flaps - Reconstruction - Post malignancy-Oncoplastic.

\section{INTRODUCTION}

With the advent of microsurgical free tissue transfer in head and neck reconstruction, local and locoregional flaps tend to lose some popularity [1]. However, free flaps are still technique-sensitive, time consuming procedures, necessitate adequate blood vessels with careful monitoring and also not suitable in some patients [2]. In the other hand, some surgeons become more reluctant the select the option of free tissue transfer when lackingof expertise and advanced equipment andwith more the interest of cost-effective medicine as well [1].

For these reasons, in reconstruction of head and neck defects, local and locoregional flaps are very helpful [1]. By considering multiple criteria in each flap, the reconstruction of defects could be individualized by judgement of these cases and the more suitable flap for each. The defect management is related to many factors such as defect site, size, patient comorbidity as well as the etiology of the defect weather traumatic or post malignancy which necessitates some specialized management and reconstruction as well [3].

Modern trends in post malignancy reconstruction target more aesthetic and functional outcome with more patient satisfaction [1].

From the oncological point of view, flap reconstruction of the defects should be compatible with some oncological considerations like cervical lymph node dissection and radiotherapy. Technical, aesthetic and functional factors are also so important in the reconstruction decision [3].

The submental island flap based on the submental artery has become more popular in head and neck reconstruction and well suited for defects of the oral cavity [1]. However, the latissimus dorsi musculocutaneous pedicled flap has its advantages in the head and neck reconstruction as it has large surface area, great arc of rotation and high ability to cover distal (cephalad) defects when compared with any pedicled musculocutaneous flap used in reconstruction of head and neck. Also, this flap provides non-irradiate tissues as the flap is totally outside the field of radiotherapy when used in management of previously irradiated head and neck malignancy [4]. Deltopectoral flap has its 
advantages of having an easy technique with dependable pedicles. Also, it has good color match with the face [5]. Paramedian Forehead flap is an axial flap based on supratrochlear artery which is very useful for repair of nasal defects with good functional and cosmetic outcome $[\mathbf{3 , 1 0}$. The nasolabial flap usually used for facial defects especially nasal reconstruction because of its unique colour and texture match to that of the nose [6]. Anteriorly based cervicofacial flap is a large rotational flap, needingwide undermining flap that be able to reconstruct a sizable defect without leaving a sizable donor one. If the dissection level in the subcutaneous plane, this flap has a randomly pattern blood supply but with multiple perforators such as deep and transverse facial arteries. However, if the plane of dissection was deep to superficial musculoapponeurotc system and platysma it attains an axial blood supply becoming an axial flap [7].

Focused evaluation of the multiple advantages and disadvantages of this armamentarium of available flaps in a novel scoring system became our motive in order to maximize the benefits of this multifactorial approaches.

This study aims to evaluate the importance of oncological, technical, aesthetic and functional considerations in selection between different types of local and locoregional flaps used in head and neck oncoplastic reconstruction. These flaps were having different examples of blood supply pattern as being random, pedicled island and pedicled non island flaps to propose a novel scoring system in selection of an ideal local and locoregional flap for oncoplastic head and neck reconstruction.

\section{PATIENTS AND METHODS}

52 local and locoregional flaps were created in 52 patients who were squeduled for head and neck tumour resection and defects reconstruction. 28 patients needed cervical lymph nodes dissection. These patients have been classified into six groups according to the flaps used in reconstruction of the defects; 11 submental pedicled flaps and 4 latissimus dorsipedicled flaps, 11 deltopectoral flaps, 8 paramedian forehead flaps, 10 nasolabial flaps and 8 anteriorly based cervicofacial flaps were created.

The data were collected as a prospective study throughout a 2-year period. The protocol of the study has been approved by Ethical Committee of ZagazigUniversity Hospital.

Age, gender, type, site of tumor, site and size of defects which has been reconstructed, type of the flap used and complications, operative findings and outcomes of the reconstructions, were reviewed.

Oncological and technical considerations were reviewed in each case postoperatively. A questionnaire shared by three plastic surgeons in aesthetic and functional ones except patient opinion which were reported 3 to 6 months after reconstruction. (Table 1).

\section{Operative techniques: \\ Submental flap:}

At the border of the lower mandibular arch the upper flap boundary is marked with determination of the lower boundary by a pinch test. The flap length can be totally or partially span from both mandibular angles designed according to the defect size. The incision of the skin paddle wascontinued with the incision of the cervical lymph nodes dissection weather unilateral or bilateral neck dissectionwas performed. Firstly, the inferior incision of the flap with the neck dissection incision are were until reach the subplatysmal plane. Submandibular gland was excised with great care to the preserve submental vessels on its superior surface. Afterwards, the course of the submental vessels was followed. Elevation of the submental flap in the subplatysmal plane from the non-pedicle side going medially to the midline then the dissection become deeper to the digastric muscle in the pedicle side. A calf of mylohyoid muscle also was included as a deep level of dissection to protect the submental vessels and its perforators as a useful modification of the traditional technique. The more length of the pedicle needed the more proximal dissection was done. Tunneling of the floorof the mouthtunnel was performedwith average size i.e. passing two fingers with ease, through the submandibular triangle to pass the flap to the mouth cavity when needed for tongue or other intraoral reconstruction. Primary closure of the donor site with undermining of the posterior border of it and putting a vacuum drain.

\section{Pedicled latissimus dorsimyocutanous flap:}

According to the defect needed to be covered, a skin territory is designed over the latissimus dorsi muscle with suitable site, orientation and size taking care to have a width less than $8 \mathrm{~cm}$ to permit direct closure of the donor site. The skin island associated with the whole latissimus dorsi muscle are included after separation from the dorsolumbar origin and the humeral insertion being only attached to thoracodorsal pedicle. A tunnel is made between the pectoralis major muscle and the clavicle allow- 
ing the flap to reach the recipient site without tension. Closure of the donor site in layers with preferable more than one vacuum drain for a prolonged period aiming to minimize the incidence of seroma or hematoma collection which are not uncommon complications in these flaps for large surface area dissection.

\section{Deltopectoral flap:}

An axial pattern fasciocutaneous flap based on the 2nd and 3rd internal mammary artery major perforators in the $2^{\text {nd }}$ and $3^{\text {rd }}$ intercostal spaces, $2 \mathrm{~cm}$ lateral to the sternum. Minor perforatorsin the $1^{\text {st }}$ and $4^{\text {th }}$ spaces can also be used associated with the major perforators. The flap is marked from the sternal border laterally to the deltoid area. For increasing distant point reach of the flap in head and neck reconstruction, different modifications were done. Extension of the lateral limit of the flap into the tip of the shoulder or even the upper lateral arm was done for this purpose with increasing the risk of partial flap loss. Pre-expansion or delay procedure which is performed byelevation of the flap and return it back to the donor site or incising it in a separate preliminary stage for days or weeks to help in reorientation of the flap blood supply and minimizing flap loss after reconstruction. The flap is generally transferred as a twostage procedure, one for defect coverage and the other for flap separation after three or four weeks, but in an attempt to convert that to a single stage the skin between the defect and the flap pedicle is simply incised to let the proximal part of the flap, nearby the pedicle, be included in the neck skincircumference. Closure of the donor site may be allowed primarily especially in old patients with redundant skin otherwise partial skin thickness graft was needed.

\section{Paramedian forehead flap:}

An axial flap based on supratrochlear artery which is exiting the orbit at the supraorbital rim level lateral to the midline by 1.7 to $2 \mathrm{~cm}$. The flap consists of skin and subcutaneous tissue with the deeper frontalis muscle and the associated fascia. The flap is marked by using of a template for accurate design which is surgically and cosmetically critical. The pedicle is narrowed as we go near the pedicle with minimal width of $1.5 \mathrm{~cm}$. Harvesting of flap was started after injecting a vasoconstricting solution. To allow for ease rotation, the contralateral side to the defect can be used except if there is a scar or other contraindication. When starting to harvest the tip, the skin and subcutaneous tissue are incised were elevated using skin hooks. After mobilization of the flap tip, finger dissection is done going deep to the galea layer in the intermediate part of the flap. Once we reach the level of superior aspect of the eye brow the dissection is deepened subperiosteally using 15 blade then a blunt dissector to protect the pedicle which penetrate the frontalis muscle at this level. We stop dissection if the flap reaches the defect without tension or if not, we may continue dissection under the corrugator muscle to provide an additional length. Closure of the donor site may need a skin flap or may occur primarily with better aesthetic outcome especially when reconstructing a small sized defect or in old aged patients with redundant forehead skin.

\section{Nasolabial flap:}

The nasolabial flaps aregenerally used for facial defects especially nasal reconstruction because of its unique colour and texture match to the nasal skin. Although of being a non-axial flap when using the skin or fasciocutaneous parts only, the nasolabial flap has a rich blood supply and harvested as a pedicled thin flap not considering 3:1 length to width ratio, as typically considered in random patterned flaps. The flap marking is performed with a lap pad using a reverse Gillie test to insure adequate length for flap rotation. Also, a template of the defect is created by foil and then marked along the donor site in the nasolabial fold and the inferomedial incision margin is usually placed along the nasolabial crease resulting in a hidden donor site scaring. The flap is dissected and elevated sharply along its borders to the mid-cheek level. Then it is dissected bluntly to the flap base. When needing thin contour, the flap is thinned leaving a minimal subcutaneous fat or only to the level of deep dermal layer. Careful flap insetting is done under little tension. The second stage of separation is usually after three weeks. Single stage flap design can used as a useful modification in certain cases.

\section{Anteriorly based cervicofacial flap:}

The flap has been usually used for cheek defects. After defect preparation, extension of incision from its lateral aspect inferior to the ear lobule and may reach nearby the tip of the mastoid process. The dissection plane was deep to the superficial musculoaponeurotic system (SMAS) in the face and in subplatysmal plane in the neck to enforce the flap vascularity. Care of unintentional injury of the marginal mandibular branch of the facial nerve near the lower mandibular border must be taken. The lateral incision extends downward and backward for a length nearly equals the defect diameter 
then the inferior incision is directed medially at ninety-degree angle or less according to the cervical skin redundancy that facilitates closure donor site angle i.e. old patients usually have more neck skin laxity which is of great help in this step. Closure of the donor site occurs primarily, with VY advancement or rarely necessitates a skin graft. Regarding the area of defect coverage, a dogear deformityoftenhas occurredin the inferomedial area of the defect closure and may be managed at the same time of reconstruction or later in a separate step for avoidance of flap vascularity compromise.

\section{RESULTS}

Fifty-two patients with head and neck tumours were managed in Zagazig University Hospitals in multidisciplinary team approach by onco-surgeons and reconstructive surgeons. As regards to the variations of pre-requisites, operative findings and outcomes of reconstructions, twenty considerations; grouped as oncological, technical, aesthetic and functional considerations were reported in each case separately (Table 1).

All positive considerations were grouped and compared in each flap type with the other types. (Tables 2,3,4,5 respectively).

Table (1): An example of a flap OTAF considerations fulfillment for a given reconstruction. The OTAF score (oncological, technical, aesthetic and functional score) is the number of positive items in each group i.e. in this case O2/T5/A6/F3.

Considerations Fulfillment

Positive or

Case no. 24 (Anterior basedcervicofacial flap for cheek reconstruction) non-conflicting

Oncological:

1- Compatibility with cervical dissection if needed
2- Compatibilitywith radiotherapy if needed

Technical:

3- Positive defect coverage regarding size and arc of rotation

4- Positive defect coverage regarding distal point reach

5- Safe to harvest; no potential to injure precious structures

6- Pliability and 3D fabrication potential if needed

7- Single stage procedure

8- Short hospitalization period (one-day surgery procedure)

9- Rapid to harvest (less than one hour)

10- Compatibility with critical patient general condition

Aesthetic:

11- Preserving the original form of the reconstructed area

12- Limited Length of the incision

13- Adequacy to fill the contour of the reconstructed defect

14- Absence of donor site defect or graft

15- Color, nature, texture and hair bearing match

16- Obtaining a good aesthetic outcome

17- Optimal patient satisfaction

Functional:

18- Good facial motor function

19- Good specialized sites function (i.e. oral cavity, nasal cavity, tongue or eye lids according to the reconstructed part)

20- No or minimal donor site functional morbidity

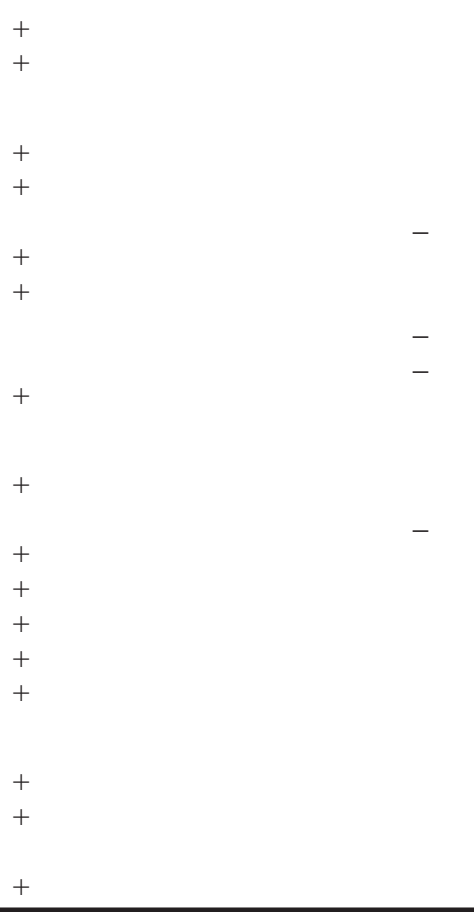

N.B.: The first and second oncological and first and second technical considerations are obligatory. The item is counted positive if it has fulfilledor not conflicting with the consideration. By using these considerations, every flap has been evaluated and scored by summation of its positive considerations in each category for example: The OTAF score of anterior based cervicofacial flap for cheek reconstructionin case no. 24 was $\mathrm{O} 2 / \mathrm{T} 5 / \mathrm{A} 6 / \mathrm{F} 3$.

Table (2): Oncological considerations fulfillment (no. of positive cases) of 6 types of flaps in 52 cases after tumour resection and defects reconstruction.

\begin{tabular}{lcccccc}
\hline $\begin{array}{l}\text { Oncological } \\
\text { Considerations }\end{array}$ & $\begin{array}{c}\text { Submental flap } \\
\text { 11 cases }\end{array}$ & $\begin{array}{c}\text { Pedicled } \\
\text { latissimus } \\
\text { dorsi 4 cases }\end{array}$ & $\begin{array}{c}\text { Deltopectoral } \\
\text { flap 11 cases }\end{array}$ & $\begin{array}{c}\text { Head flap } \\
8 \text { cases }\end{array}$ & $\begin{array}{c}\text { Nasolabial flap } \\
\text { 10 cases }\end{array}$ & $\begin{array}{c}\text { Anteriorly based } \\
\text { cervicaofa 8 cases }\end{array}$ \\
\hline $\begin{array}{c}\text { 1- Compatibility with } \\
\text { cervical dissection } \\
\text { if needed }\end{array}$ & 10 & 4 & 11 & 8 & 10 & 8 \\
$\begin{array}{c}\text { 2- Compatibilitywith } \\
\text { radiotherapy } \\
\text { if needed }\end{array}$ & 9 & 4 & 11 & 8 & 10 & 8 \\
\hline
\end{tabular}


Table (3): Technical considerations fulfillment (no. of positive cases) of 6 types of flaps in 52 cases after tumour resection and defects reconstruction.

\begin{tabular}{|c|c|c|c|c|c|c|}
\hline $\begin{array}{l}\text { Technical } \\
\text { Considerations }\end{array}$ & $\begin{array}{l}\text { Submental } \\
\text { flap } \\
11 \text { cases }\end{array}$ & $\begin{array}{c}\text { Pedicled } \\
\text { latissimus } \\
\text { dorsi } 4 \text { cases }\end{array}$ & $\begin{array}{l}\text { Deltopectoral } \\
\text { flap } 11 \text { cases }\end{array}$ & $\begin{array}{l}\text { Head flap } \\
8 \text { cases }\end{array}$ & $\begin{array}{l}\text { Nasolabial } \\
\text { flap } 10 \\
\text { cases }\end{array}$ & $\begin{array}{c}\text { Anteriorly } \\
\text { based } \\
\text { cervicaofa } \\
8 \text { cases }\end{array}$ \\
\hline $\begin{array}{l}\text { 3- Positive defect coverage regarding } \\
\text { size and arc of rotation }\end{array}$ & 9 & 4 & 9 & 7 & 7 & 6 \\
\hline $\begin{array}{l}\text { 4- Positive defect coverage regarding } \\
\text { distal point reach }\end{array}$ & 8 & 4 & 8 & 7 & 7 & 7 \\
\hline $\begin{array}{l}\text { 5- Safe to harvest; no potential to } \\
\text { injure precious structures }\end{array}$ & - & - & 11 & 8 & 8 & 5 \\
\hline $\begin{array}{l}\text { 6- Pliability and 3D fabrication } \\
\text { potential if needed }\end{array}$ & 9 & 3 & 11 & 8 & 8 & 8 \\
\hline 7- Single stage procedure & 10 & 2 & 3 & - & - & 7 \\
\hline $\begin{array}{l}\text { 8- Short hospitalization period (one- } \\
\text { day surgery procedure) }\end{array}$ & - & - & - & 6 & 6 & - \\
\hline $\begin{array}{l}\text { 9- Rapid to harvest (less than one } \\
\text { hour) }\end{array}$ & - & - & 7 & 6 & 6 & - \\
\hline $\begin{array}{l}\text { 10- Compatibility with critical patient } \\
\text { general condition }\end{array}$ & 6 & - & 11 & 8 & 8 & 6 \\
\hline
\end{tabular}

Table (4): Aesthetic considerations fulfillment (no. of positive cases) of 6 types of flaps in 52 cases after tumour resection and defects reconstruction.

\begin{tabular}{|c|c|c|c|c|c|c|}
\hline $\begin{array}{l}\text { Aesthetic } \\
\text { Considerations }\end{array}$ & $\begin{array}{l}\text { Submental } \\
\text { flap } \\
11 \text { cases }\end{array}$ & $\begin{array}{c}\text { Pedicled } \\
\text { latissimus } \\
\text { dorsi } 4 \text { cases }\end{array}$ & $\begin{array}{l}\text { Deltopectoral } \\
\text { flap } 11 \text { cases }\end{array}$ & $\begin{array}{l}\text { Head flap } \\
8 \text { cases }\end{array}$ & $\begin{array}{l}\text { Nasolabial } \\
\text { flap } 10 \\
\text { cases }\end{array}$ & $\begin{array}{c}\text { Anteriorly } \\
\text { based } \\
\text { cervicaofa } \\
8 \text { cases }\end{array}$ \\
\hline $\begin{array}{l}\text { 11- Preserving the original form of the } \\
\text { reconstructed area }\end{array}$ & 6 & 3 & 2 & 6 & 10 & 7 \\
\hline 12- Limited Length of the incision & 8 & - & - & 7 & 7 & 2 \\
\hline $\begin{array}{l}\text { 13- Adequacy to fill the contour of the } \\
\text { reconstructed defect }\end{array}$ & + & + & + & + & + & + \\
\hline $\begin{array}{l}\text { 14- Absence of donor site defect or } \\
\text { graft }\end{array}$ & 10 & 1 & - & 6 & 10 & 7 \\
\hline $\begin{array}{l}\text { 15- Color, nature, texture and hair } \\
\text { bearing match }\end{array}$ & - & - & 9 & 6 & 10 & 7 \\
\hline 16- Obtaining a good aesthetic & 8 & - & 9 & 7 & 9 & 8 \\
\hline 17- Optimal patient satisfaction & 7 & - & - & 7 & 10 & 8 \\
\hline
\end{tabular}

Table (5): Functional considerations fulfillment (no. of positive cases) of 6 types of flaps in 52 cases after tumour resection and defects reconstruction.

\begin{tabular}{|c|c|c|c|c|c|c|}
\hline $\begin{array}{l}\text { Functional } \\
\text { Considerations }\end{array}$ & $\begin{array}{l}\text { Submental } \\
\text { flap } \\
11 \text { cases }\end{array}$ & $\begin{array}{c}\text { Pedicled } \\
\text { latissimus } \\
\text { dorsi } 4 \text { cases }\end{array}$ & $\begin{array}{l}\text { Deltopectoral } \\
\text { flap } 11 \text { cases }\end{array}$ & $\begin{array}{l}\text { Head flap } \\
8 \text { cases }\end{array}$ & $\begin{array}{l}\text { Nasolabial } \\
\text { flap } 10 \\
\text { cases }\end{array}$ & $\begin{array}{l}\text { Anteriorly } \\
\text { based } \\
\text { cervicaofa } \\
8 \text { cases }\end{array}$ \\
\hline 18- Good facial motor function & 10 & - & - & 7 & 10 & 7 \\
\hline $\begin{array}{l}\text { 19- Good specialized sites function } \\
\text { (i.e. oral cavity, nasal cavity, } \\
\text { tongue or eye lids according to } \\
\text { the reconstructed part) }\end{array}$ & 8 & 3 & - & 8 & 9 & 7 \\
\hline $\begin{array}{l}\text { 20- No or minimal donor site } \\
\text { functional morbidity }\end{array}$ & 9 & - & 10 & 7 & 9 & 7 \\
\hline
\end{tabular}



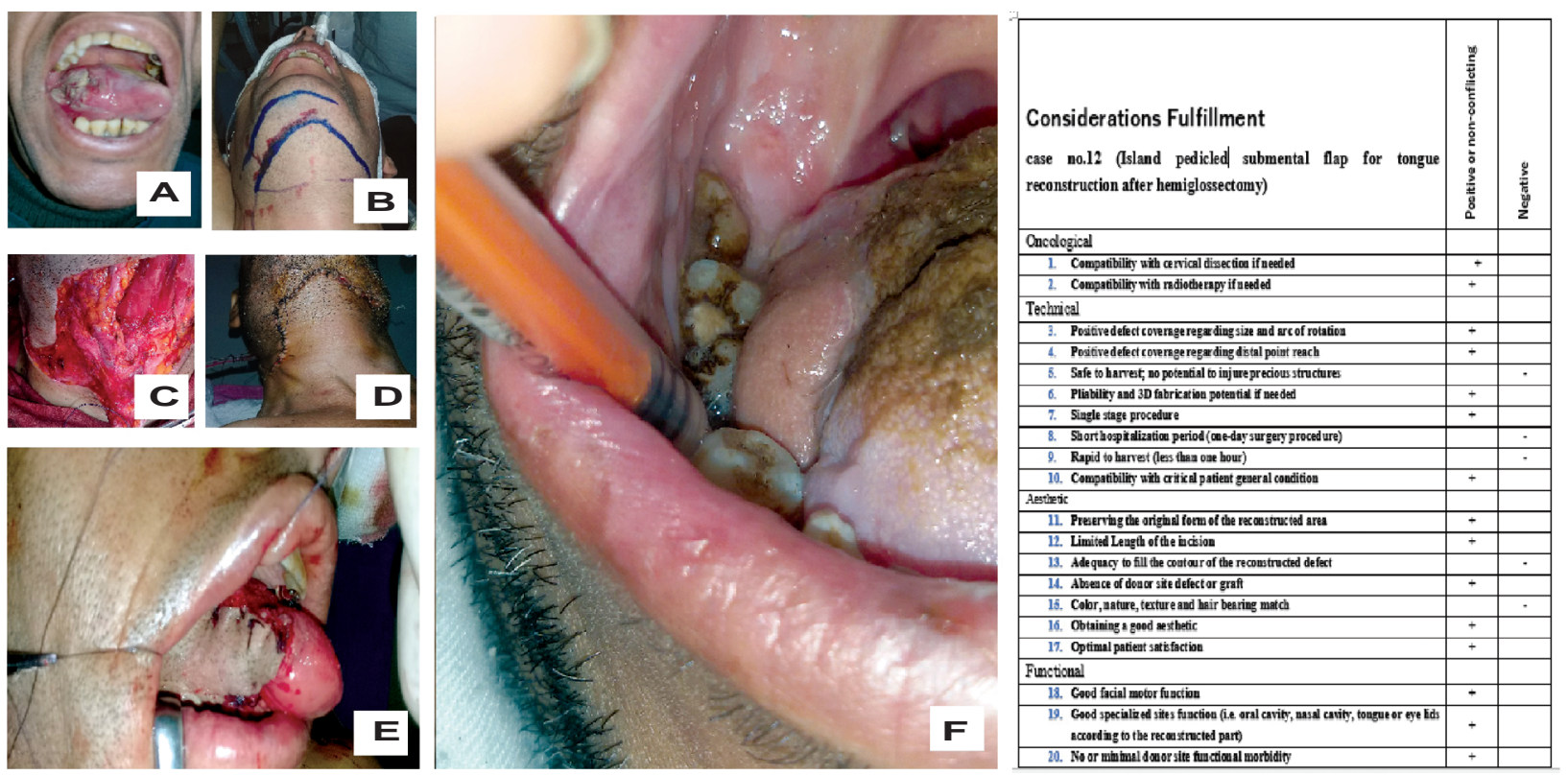

Fig. (1): Case No. 18: The OTAF score of the submental flap for tongue reconstruction after hemiglossectomy O2/T5/A5/F3. APreoperative view: Scc of the right side of the tongue, B- Marking of the submental flap, C- Right side block nech dissection, D- Primary closure of the flap donor site, E- Immediate postoperative view after hemiglossectomy and flap reconstruction, F- Postoperative view after 4 months follow-up with spontaneous flap skin changes to be like the oral mucosa.
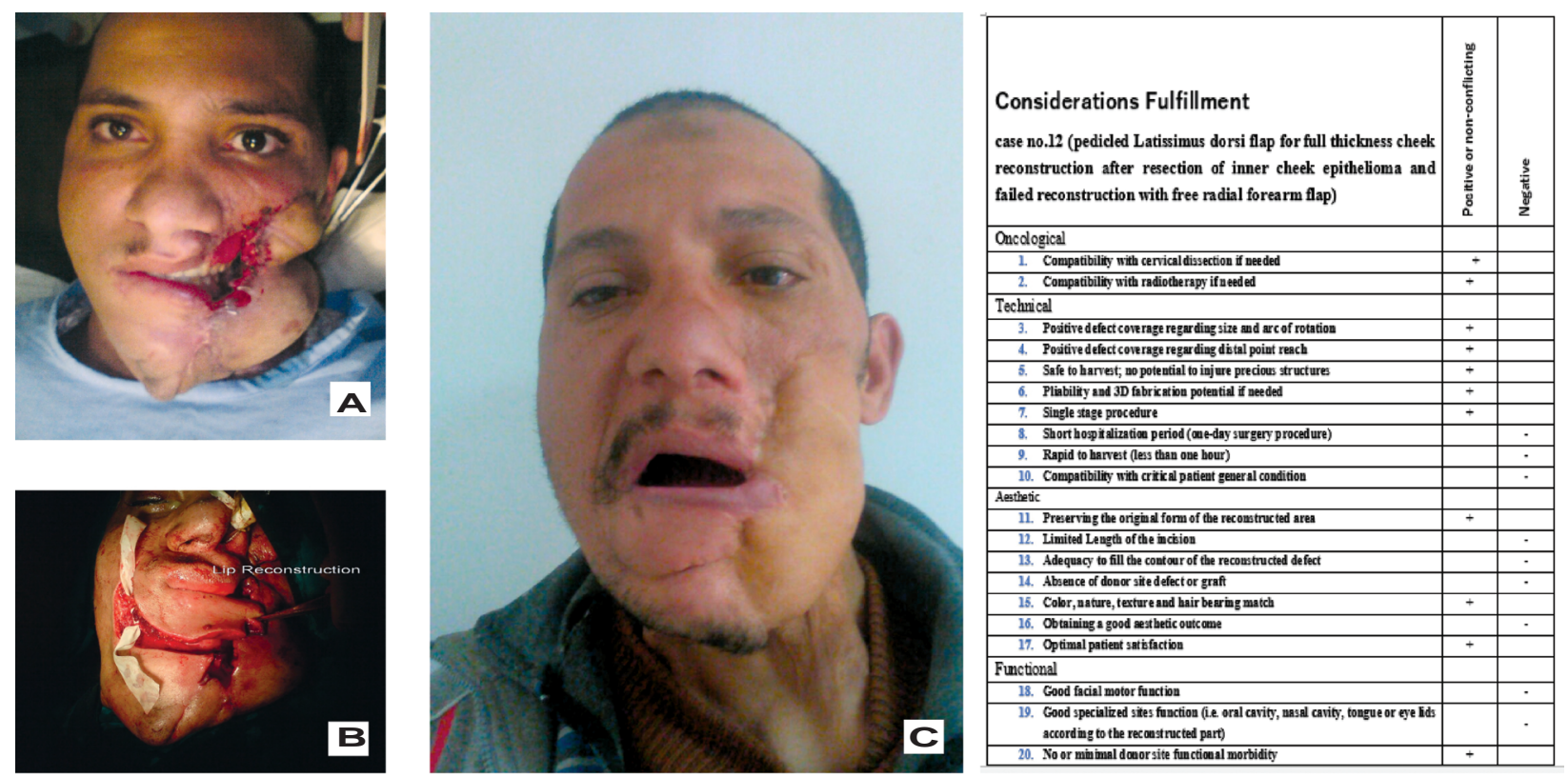

Fig. (2): Case No. 12: The OTAF score of pedicled latissimus dorsi flap for full thickness cheek reconstruction after resection of inner cheek epithelioma and failed reconstruction with free radial forearm flap O2/T5/A3/F1. A- Full thickness left cheek defect reconstructed with bilobedpedicled latissimus dorsi flap, B- Lip reconstructed by advancement, C- Late follow-up view after one year. 

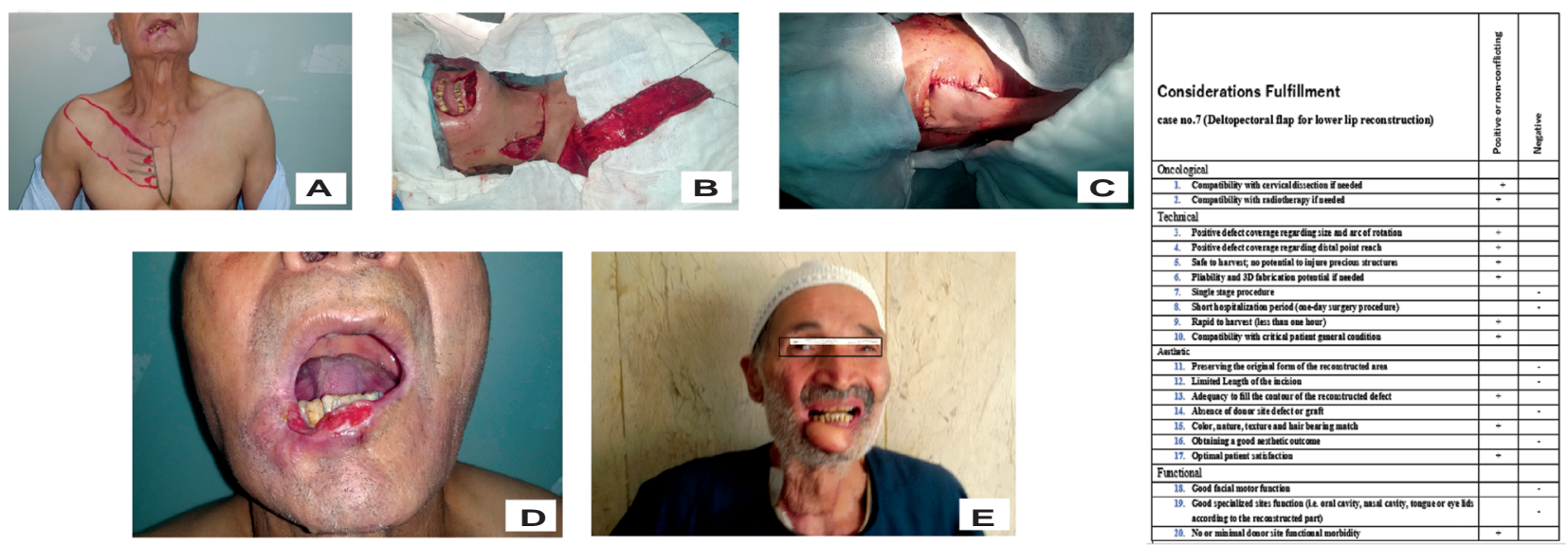

Fig. (3): Case No. 7: The OTAF score of deltopectoral flap for lower lip reconstruction O2/T6/A3/F1. A- Donor area of the deltopectoral flap by second and third perforators of internal mammary vessels, B- Resection of the tumour with suprahyoid neck dissection and elevation of the deltopectoral flap, C- Flap insetting to the lower lip defect, D- Preoperative view E- Postoperative view after 5 months of follow-up.
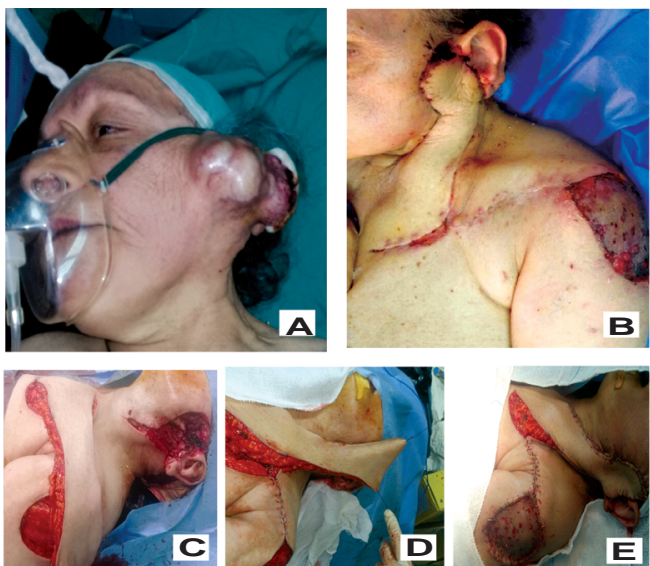

C
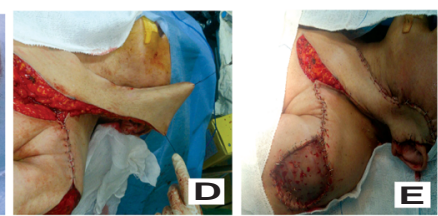
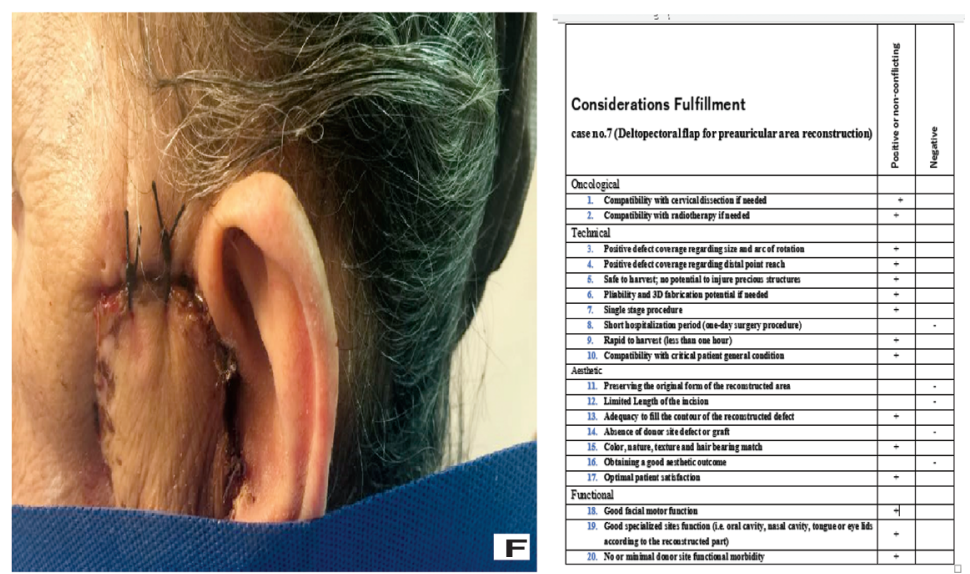

Fig. (4): Case No. 9 : The OTAF score of deltopectoral flap for preauricular skin reconstruction O2/T7/A3/F3. A- Preoperative view with critical general condition which is not suitable for prolonged complicating surgery, B- Postoperative view 14 days after operation; note that the cervical skin was incised and the pedicle of the flap was included in to convert the transfer to a single staged procedure, C- Intraoperative view after parotidectomy with extensive skin defect, D- Closure of the donor site withpatial skin closure and the remaining part necessitated a skin graft, E- Immediate postoperative view, F- Three weeks postoperative view.
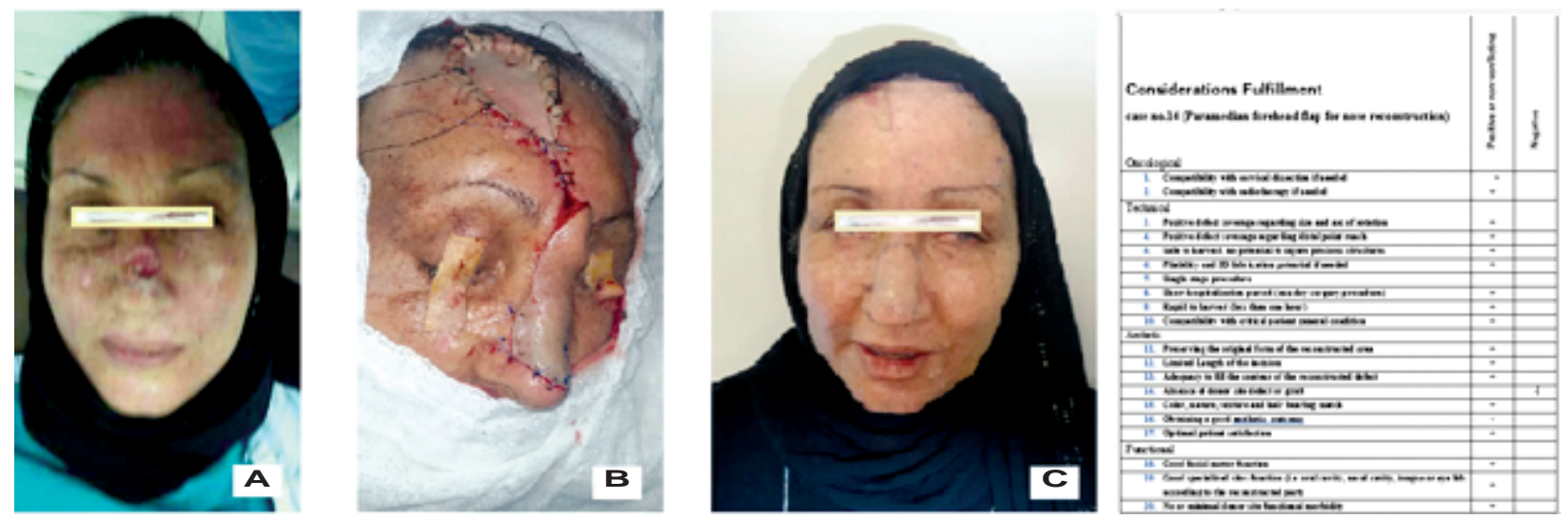

Fig. (5): Case No. 14: The OTAF score of paramedian forehead flap for nose reconstruction O2/T7/A6/F3, A- Preoperative view (scc), B- Coverage of the defect after resection of the lesion with skin graft to the donor site, C- Final view after the second stege (separation); note the size of the skin graft on the donor site was minimized with the spontaneous graft contracture. 

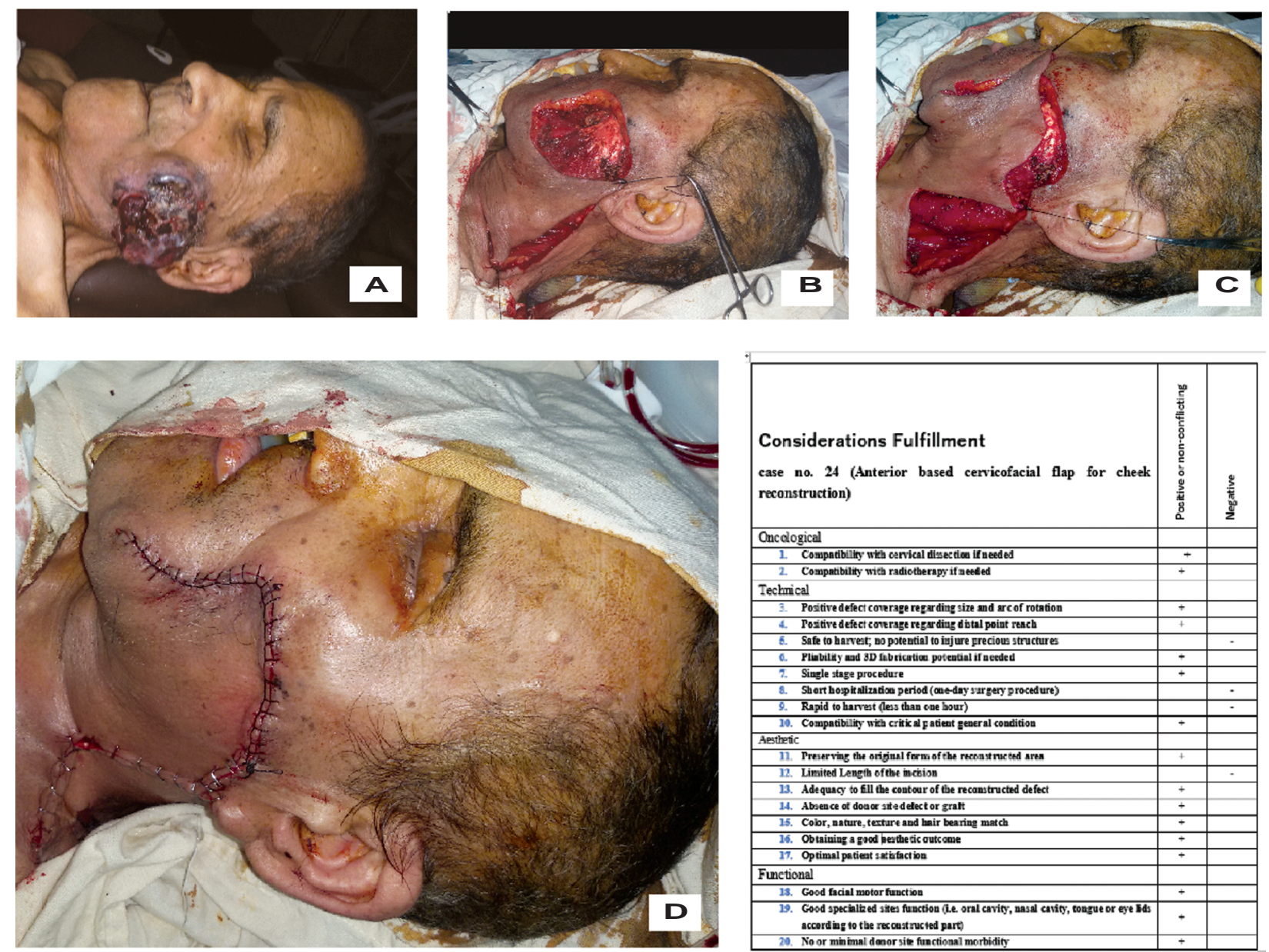

Fig. (6): Case No. 24: The OTAF score of anteriorly based cervicofacial flap for cheek reconstruction O2/T5/A6/F3. A- Preoperative view, B- Extensive cheek defect post resection with subplatysmal dissection; taking care not to thin the flap or injure the marginal mandibular nerve nearby the lower mandibular border, C-Coverage of the defect as a rotational flap. A dog ear is formed in the lower medial part of the defect cautiously managed not to impair the flap vascularity.

\section{DISCUSSION}

The current study evaluates different twenty considerations used in selection of the local and locoregional flaps used in fifty-two cases of post malignancy head and neck reconstruction. These considerations were classified into four main groups; oncological, technical, aesthetic and functional considerations. The fifty-two patients' defects in the current study were reconstructed with six different types of flaps.

\section{Oncological considerations:}

Regarding the oncological considerations, compatibility of the used flap with cervical lymph nodesdissectionprocedure or radiotherapy, if needed, was of utmost importance. However, if the site of the flap harvesting or insetting is not involved in cervical dissection procedure or radiotherpy the flap was considered compatible oncologically. In the other hand, in the present study, some flaps have required further precautions. Regarding the submental flaps, cautious excision of the submandibular gland and avoiding submental vessels injury on its superior surface and level 1B lymph node dissection (submandibular L.N.) so achieving a thorough lymphadenectomy. In the present study, cervical dissection was done in these cases with cautious pedicle dissection and contralateral submental flap was not needed except in two cases. This agree with the review of Urjeet et al., regarding the oncological safety of the submental flap when used post oral malignancy and did not report any compromise of oncologic outcome. Also, random anteriorly based cervical flap did not show any vascular compromise with thorough cervical Lymph node dissection and considered compatible with cervical dissection [1]. Furthermore, in agreement with Binelfa LF in 2010, pedicled latissimus dorsi flap has the privilege of being outside the radiation field if prior radiotherapy was used. So, it provides tissues not exposed for radiation and the flap itself 
not affected cervical dissection before reconstruction. Hence, it is considered an oncologically compatible flap [1].

\section{Technical considerations:}

Technical considerations were reported in the cases of the current study. The abilities of a flap to cover defects completely regarding its size, arc of rotation or distal point reach are considered critical to achieve the target of reconstruction. The present study revealed that the pedicled latissimus dorsi flap showed the unique potential to cover extensive large defects, distal reach point and great arc of rotation which is consistent with Binelfa [11] in the other hand, Agbara et al., reported that the forehead flap can provides distal reach of adequate tissue both from internal oral lining and external cover that can be used to cover defects to the level of the lower mandibular border [12]. However, in the present study none of forehead flap was found to reach beyond the midface. Nasolabial flap was reported by Multani et al., [3] as an ideal source for nasal reconstruction and the flap can reconstruct outer or inner lining of nasal defects in consistence with the current study. As regards to the safety to harvest island submental flap, during excision of the submandibular gland it must be performed with attention to the submental vessels on the superior glandular surface otherwise the pedicle could be injured [1]. In the present series, the proximal part of facial artery was injured and ligated in one case but the flap blood supply was not compromised as the flap received reversed flow from the distal part of the facial artery. Also, in seven supmental flaps, we used a mylohyoid muscle as a calf to protect the pedicle with easier technique and better survival. This modification was supported by Urjeet et al., [1] as a useful modification. In consistent to the current study, the ability to separate the pedicled latissimus dorsi into two vascularized paddles due to early division of the thoracodorsal vessels provided full thickness cheek reconstruction privilege which enhance the fabrication property of this flap in agreement with Binelfa [11]. Another factor was experienced in deltopectoral flap which is the technical simplicity with thin and pliable skin paddle. The same comment was concluded by Bey et al., in their work in 2009 [14]. The simple operative technique of anteriorly based cervicofacialflap motivated Agbara et al., to use that flap in a series of cases as it was a good option for cheek reconstruction [12]. Island flaps are technique sensitive and may be time consuming in dissection of the pedicle but the time decline with learning curve. Deltopectoral, nasolabial and forehead flaps did not show technical difficulty nor being time consuming operation regarding their dissection. In anteriorly based cervicofacial flaps, the time was consumed in careful dissection and meticulous hemostasis. Tollefson et al. reported that undermining of the flap should be sufficient to avoid closure under tension. Also, the risk of hematoma could be reduced by meticulous hemostasis [13].

Regarding the need for a second stage, Quillen and Ariyan identified the role of single-stage pedicled flap in head and neck reconstruction the late 1970s [11].

In the current study, pedicled non-island flaps like deltopectoral, forehead and some nasolabial flaps that usually have needed other stage for pedicle separation and flap refinement. However, this was not a sharp role with these flaps. Four cases of deltopectoral flaps in the present study were converted into single stage procedures to save another procedure in critically ill patients by cutting the skin between the defect and the flap to let the proximal part of the flap, nearby the pedicle, be included in the neck skin circumference. In the other hand, island flaps, that are traditionally single staged, may need second stage for cutting the tethered pedicle after adequate local flap revascularization. Also, two random flaps needed second stage for dog ear removal and aesthetic flap refinement.

\section{Aesthetic considerations:}

Modern head and neck reconstruction tends to have more cosmetically appealing results in order to preservation of the original form of those reconstructed areas [1]. Rotunda AM et al., [15] concluded in their work that nose is one of the most challenging reconstruction in the facial areas and most demanding to obtain an optimal functional and esthetic results. Color matching is one of the most important characters in the selection of the reconstructing flap. Multani et al., reported in their review that nasolabial flaps in nasal reconstruction were the ideal source regarding color, nature and texture match. Furthermore, donor site morbidity is minimal owing to placing its scar along the nasolabial fold [3]. In the present study, also, we reported maximal color, nature and texture match with nasolabial flap in nasal reconstruction when achievable. The same results were shown by Hagerty et al., [16] for partial nasal reconstruction. Bakamjian et al., revealed the high suitability of deltopectoral flap for head and neck defects covering due to the similarity of color and texture of skin with hidden donor site $[\mathbf{8 , 1 7 ]}$. We agreed with the results of Bakamjian except in some males 
with hairy chests. In these cases, deltopectoral flaps showed some nature and hair bearing mismatch when used in reconstruction of non-hair bearing head and neck areas. Two cases necessitated laser hair ablations of the transported flap area after lip reconstruction which solved this problem. In the other hand, men underwent tongue reconstruction using submental flap in the current study complained from hair growth in the newly reconstructed tongue which was completely disappeared by the end of the first year. In consistence with our results, cheek reconstruction by latissimus dorsi flap is characterized by little hair contained in the skin of the flap donor site [18]. The submental flap was de-epithelialized by Rahpeyma at the time of inset to eliminate the hair follicles surgically [19]. the anteriorly based cervicofacial flap is a good option for cheek reconstruction due to its proximity to the surgical area, and easily elevation and insetting to the reconstructed area. The flap is thin, pliable flap, usually has not required other donor site graft and resulted in an acceptable scar [12]. In the current study, each flap with suitable contour was selected for each defect. Submental flaps were found thin and were used for intraoral reconstruction. However, Pedicled latissimus dorsi flap were found to be bulky and were suitable in extensive cheek reconstruction. Deltopectoral flap showed an average contour for medium thickness defects.

\section{Functional considerations:}

Normal or near normal functional result either in the recipient or donor site is a golden target in modern head and neck reconstruction. The present study evaluated this target in three parameters i.e. global facial function, specialized sites function (i.e. oral cavity, nasal cavity, tongue or eye lids according to the reconstructed part) and donor site function as well.

Reliable restoration of facial function is a continuing challenge in head and neck reconstruction [20]. The unique anatomic association of the facial skin with the close underlying muscles allow the emotional expression and social interaction. Depending on the thickness of the used flaps in the current study, the thin flaps like nasolabial and cervical flaps have achieve better facial function preservation [9]. Bulky flaps such as pedicled latissimus dorsi flaps have impeded facial expression however their more reliability to compensate the extensive defects. In consistent to this result, depending on the flap thickness, Peng et al., reported that anteriorly based cervicofacial flap is a good candidate for cheek coverage as it is a thin and pliable flap [21]. Also, Jangpreet and his col- leagues reported in their review that deltopectoral flap were suitable coverage for head and neck skin defects and nasolabial flap are the ideal source was nasal reconstruction [22]. Regarding donor site functional affection, deltopectoral flaps reported beter functional results at the donor site than pedicled latissimus dorsimyocutanous flaps [18]. This result was comparable to the current study however, the pedicled latissimus dorsi flap has not markedly affected the shoulder function but with a patient was using crutches to support walking,he suffered some shoulder disability for a time after latissimus dorsi transfer. In other case, we preferred to use deltopectoral flap than pedicled latissimus dorsi flap to reconstruct a large post parotidectomy defect as the patient was an old woman suffering from cerebrovascular strock with right hemiparesis. The goal was to preserve her left shoulder function and not affecting it if any myocutaneous flap has been used.

\section{Conclusion:}

OTAF scoring system can be used as a simplified systematic method of flap selection for post malignancy head and neck reconstruction through using oncological, technical, aesthetic and functional considerations. Individualized selection for each case still has its place however further evaluation and modifications of this scoring system is essential to maximize the results of our reconstructive tools.

\section{REFERENCES}

1- Urjeet A. Patel, Gregory K. Hartig, Matthew M. Hanasono, Derrick T. Lin and Jeremy D. Richmon.: Locoregional Flaps for Oral Cavity Reconstruction: A Review of Modern Options. Otolaryngology-Head and Neck Surgery, 157 (2): 201, 2017.

2- Colletti G., Autelitano L., Tewfik K., et al.: Autonomized flaps in secondary head and neck reconstructions. Acta. Otorhinolaryngol. Ital., 32: 329-335. PMID: 23326014, 2012.

3- Multani J.S., Nagi G.S. and Bajwa B.B.: Local and locoregional Flaps in head and neck defects. Journal of Evolution of Medical and Dental Science, 4 (1): 12-6, 2015.

4- Rebelo M., Ferreira A., Barbosa R., Horta R., Reis J. and Amarante J.: Deltopectoral flap-an old but contemporaneous solution for neck reconstruction. J. Plast. Reconstr. Aesthet. Surg., 62 (1): 137-138. pmid: 18773875, 2009.

5- Chen, Chun-Ming Lee, Huey-Er Wu, Ju-Hui Lu, Pei-Chen $\mathrm{Du}, \mathrm{Je}-\mathrm{Kang}$ Lee and Kun-Tsung: Comparison of conventional and L-extension deltopectoral flaps in headand-neck reconstructions. Journal of Dental Sciences. 7. 179-183. 10.1016/j.jds.2012.03.016, 2012.

6- Cameron, R.R., Latham, W.D. and Dowling, J.A.: Reconstructions of the nose and upper lip with nasolabial flaps. Plast. Reconstr. Surg., 52: 145, 1973. 
7- Taub P.J.: Cervicofacial Flap. In: Anh Tran T., Panthaki Z., Hoballah J., Thaller S. (eds) Operative Dictations in Plastic and Reconstructive Surgery. Springer, Cham., 2017.

8- Makkar R.M.: The faciocervicopectoral flap for nononcological cases of cheek reconstruction. Annals of the Royal College of Surgeons of England, 95 (6): 397-400, 2013.

9- Soler-Presas F., Cuesta-Gil M., Borja-Morant A., ConcejoCutoli C., Acero-Sanz J. and Navarro-Vila C.: Midface soft tissue reconstruction with the facio-cervico-pectoral flap. J. Craniomaxillofac. Surg., 25: 39-45, 1997

10- Boyd C.M., Baker S.R., Fader D.J., Wang T.S. and Johnson T.M.: The forehead flap for nasal reconstruction. Arch. Dermatol., 136: 1365-1370, 2000.

11- Binelfa L.F.: Lattissimusdorsimyocutaneous flap in head and neck surgery. Cir.,78: 485-491, 2010.

12- Rowland Agbara, Athanasius ChukwudiObiadazie, Benjamin Fomete and Kelvin UchennaOmeje: Orofacial Soft Tissue Reconstruction with Locoregional Flaps in a Health Resource-Depleted Environment: Experiences from Nigeria. Archives of Plastic. Surgery, 43 (3): 265-271, 2016.

13- Tollefson T.T., Murakami C.S. and Kriet J.D.: Cheek repair. Otolaryngol. Clin. North Am., 34: 627-646, 2001.

14- Bey E., Hautier A., Pradier J.P. and Duhamel P.: Is the deltopectoral flap born again? Role in postburn head and neck reconstruction. Burns, 35: 123, 2009.
15- Rotunda A.M. and Bennett R.G.: The forehead flap for nasal reconstruction: How we do it. Advances in Dermatologic Surgery, 2006.

16- Hagerty R.F. and Smith W.: The nasolabial cheek flap. Am. J. Surg., 24: 506, 1958.

17- Bakamjian V.Y., Long M. and Rigg B.: Experience with the medially based deltopectoral flap in reconstructive surgery of the head and neck. Br. J. Plastic. Surgery, 174183.

18- Quillen C.G.: Latissimus dorsimyocutaneous flap in head and neck reconstruction. Plast. Reconst. Surg., 63:664$670,1979$.

19- Rahpeyma A. and Khajehahmadi S.: Oral reconstruction with submental flap. Ann. Maxillofac. Surg., 3: 144-147, 2013.

20- Mureau M.A. and Hofer S.O.: Maximizing results in reconstruction of cheek defects. Clin. Plast. Surg., 36: 461-476, 2009.

21- Peng L.W., Zhang W.F., Zhao J.H., et al.: Two designs of platysma myocutaneous flap for reconstruction of oral and facial defects following cancer surgery. Int. J. Oral. Maxillofac. Surg., 34: 507-513, 2005.

22- Jangpreet Singh Multani, Gurinderjit Singh Nagi and Baljit Singh Bajwa: "Local and Locoregional Flaps in Head and Neck Defects". Journal of Evolution of Medical and Dental Sciences, Vol. 4, Issue 01, January 01, Page: 12-16, DOI: 10.14260/jemds/2015/3, 2015. 